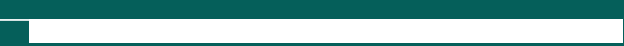

SECCIÓN: Problemas espaciales contemporáneos
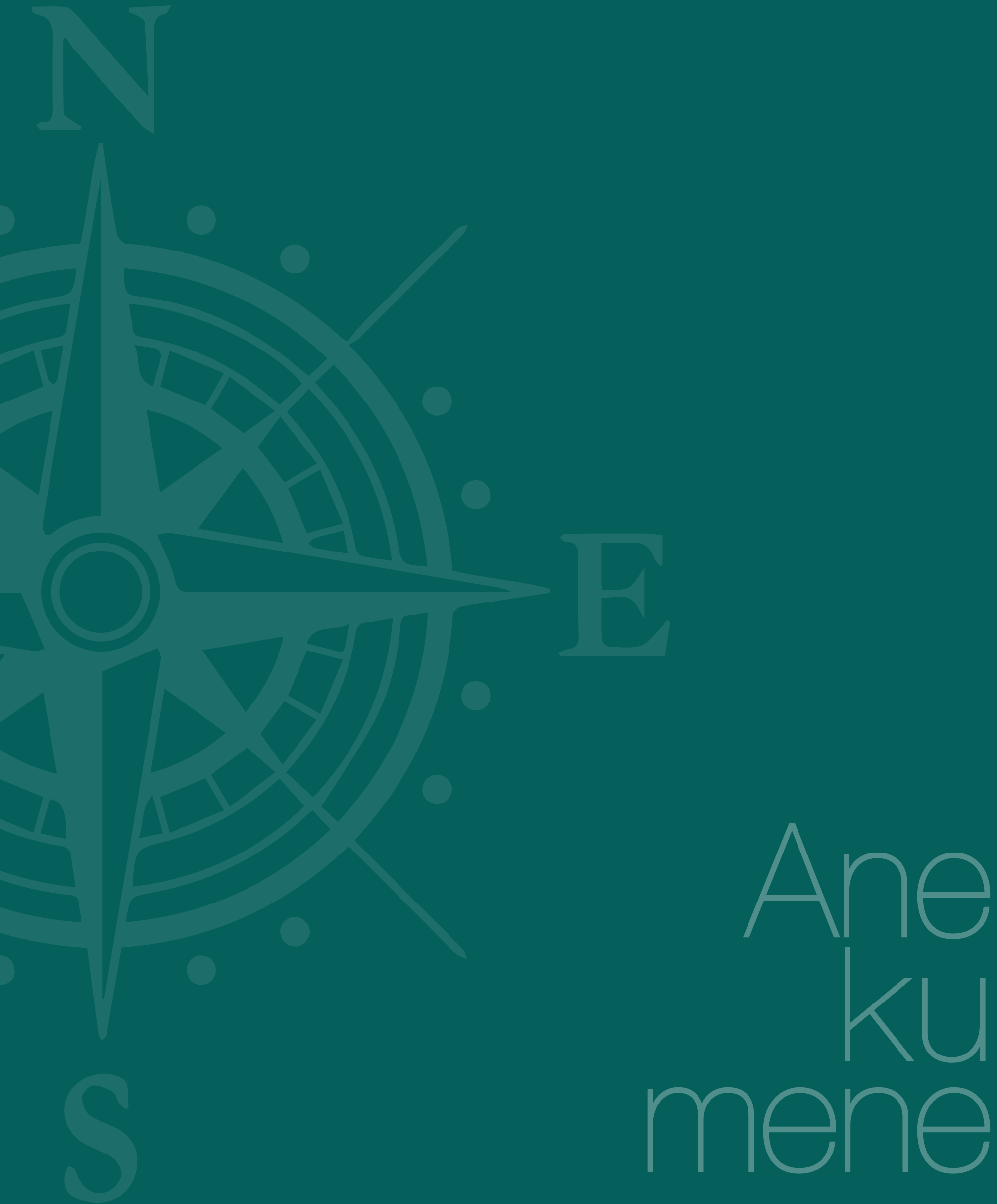


\section{Práticas de linguagem na formação de professores de geografia: uma experiência com mapas, fotografias e $o$ conceito de fronteira}

Prácticas de lenguaje en la formación de profesores de geografía: una experiencia con mapas, fotografías y el concepto de frontera

Language Practices in Geography Teachers Training: An Experience with Maps, Photography and the Concept of Border

Tânia Seneme do Canto*

\section{Resumo}

O objetivo da pesquisa é conhecer e refletir aspectos associados à comunicação e as linguagens no espaço, pois na atualidade é possível pensar as linguagens do ensino de Geografia a partir de diversas abordagens teóricas como resultado de formas distintas de entendê-las e apropriá-las. No campo da didática da Geografia, as linguagens e as diversas formas de representação são, geralmente, apreciadas como meios pelos quais crianças e jovens podem progredir na construção de conceitos e na compreensão de fenômenos espaciais.

\section{Palavras-chave}

ensino da Geografia; didática da Geografia; fenômenos espaciais 
Práticas de linguagem na formação de professores de geografia:

uma experiência com mapas, fotografias e o conceito de fronteira

Tânia Seneme do Canto /

\section{Resumen}

Interesa a la investigación conocer y reflexionar aspectos asociados con la comunicación y los lenguajes en el espacio, puesto que en la actualidad es posible pensar los lenguajes en la enseñanza de geografía a partir de diferentes enfoques teóricos, lo que resulta también de maneras distintas de entenderlos y de apropiarlos. En el campo de la didáctica de la geografía, los lenguajes y las diversas formas de representación son generalmente tomados como medios por los cuales niños y jóvenes pueden progresar en la construcción de conceptos y en la comprensión de fenómenos espaciales.

\section{Abstract}

This research aims at knowing and reflecting about comunication and languages of space; taking into account that nowadays it is possible to think about languages on geography teaching from different theoretical approaches which are also different ways of understanding and appropriation. On the field of geography didactics, languages and ways of representation are often taken as means in which children and young people can construct concepts and comprehend spatial phenomena.

\section{Palabras clave}

enseñanza de la geografía; didáctica de la geografía; fenómenos espaciales

\section{Keywords}

geography teaching: geography didactis; spatial phenomena 


\section{Introdução}

$\mathrm{Na}$ atualidade, é possível pensar as linguagens no ensino de geografia a partir de diferentes abordagens teóricas, o que resulta também em maneiras distintas de entendê-las e delas se apropriar. No campo da didática da geografia, as linguagens e as diversas formas de representação a que dão origem, são, geralmente, tomadas como meios pelos quais crianças e jovens podem progredir na construção de conceitos e na compreensão de fenômenos espaciais. Por isso, tanto nos referimos às linguagens geográficas em nossos estudos e práticas.

Este caráter mais instrumental atribuído às linguagens no ensino de geografia não pode ser subestimado, especialmente na formação dos professores, já que contribui consideravelmente para consolidar o conhecimento geográfico escolar e acadêmico como possibilidades de leitura e compreensão do mundo. Contudo, esta não é a única maneira que temos de conceber e pensar as linguagens geográficas na educação.

Quando, na chamada pós-modernidade, a linguagem foi colocada no centro do debate sobre as identidades e a complexidade da cultura contemporânea, também outro olhar foi lançado para a escola e para as diferentes práticas de linguagem que nela se dão. No mundo, nós formamos e transformamos pelos mais diversos processos de significação; na escola, o mesmo acontece. Tudo o que circula nela, incluindo as linguagens geográficas, contribui para a produção de sentido. Nesta perspectiva, algumas indagações importantes passam a ser feitas no campo do ensino de geografia. Que sentidos as linguagens geográficas têm feito circular na escola? Que sentidos outros são possíveis circular por meio delas?

Ao propormos, em um Curso de Licenciatura em Geografia no Brasil, uma disciplina eletiva denominada "Representações e Linguagens no Ensino de Geografia”, pretendíamos abordar exatamente estas questões na formação dos professores. Partimos, então, do entendimento de que, sendo o mapa e a fotografia as principais linguagens utilizadas para o ensino de geografia na escola, ambas poderiam ser focadas na disciplina. Mas como as estudaríamos? De que maneira os futuros professores poderiam compreender seus usos e funcionamento na produção de sentidos?

Buscando responder estas perguntas, pensamos em uma abordagem metodológica para a disciplina. Selecionamos o conceito de fronteira como possibilidade para estudar as linguagens cartográfica e fotográfica considerando a relação entre forma e conteúdo. Ou seja, concebemos que a compreensão acerca do modo como as duas linguagens funcionam na produção de sentidos, deveria se dar analisando as representações de fronteira que cada uma delas possibilita proliferar através dos seus elementos constituintes. Desta forma, o conceito foi utilizado como critério tanto para as atividades voltadas à seleção, quanto à criação, de mapas e fotografias na disciplina.
Diante disso, discutimos no presente trabalho algumas das atividades que desenvolvemos ao longo da disciplina, as quais podem ser separadas em dois eixos principais: a) o estudo de mapas e fotografias de livros didáticos que abordam o conceito de fronteira e $b$ ) a experimentação das linguagens fotográfica e cartográfica através de práticas que buscam alargar os sentidos de fronteira acentuados nos materiais didáticos. Antes de refletirmos sobre os resultados obtidos em ambos os eixos, começamos o texto informando sobre alguns referenciais teóricos que orientaram as escolhas feitas na disciplina e as atividades propostas.

\section{Criando uma disciplina sobre linguagens no ensino de geografia}

A disciplina "Representações e Linguagens no Ensino de Geografia" foi criada para integrar o novo currículo do Curso de Licenciatura em Geografia da Universidade Estadual de Campinas em 2016, constando como matéria obrigatória para os alunos do $5^{\circ}$ semestre do curso integral e $7^{\circ}$ semestre do curso noturno. Isso significa que somente a partir do $1^{\circ}$ semestre de 2018 a disciplina deverá ser obrigatoriamente oferecida, já que este será o momento em que os estudantes ingressantes na nova matriz curricular deverão cumprir as matérias previstas para o $5^{\circ}$ semestre do curso. Até lá, propusemos que a disciplina fosse apresentada como matéria optativa em 2016 e 2017.

Em 2016, a disciplina foi ofertada no $1^{\circ}$ semestre do ano letivo e apenas quatro alunos se inscreveram para cursá-la, sendo que um deles frequentou apenas as primeiras semanas de aula. Assim, a disciplina transcorreu ao longo do semestre com a participação de três alunos ${ }^{1}$. Deste conjunto de alunos, um deles era estudante do curso de Ciências Sociais na Universidade, enquanto os outros dois cursavam Geografia, mas estavam vinculados ao currículo antigo, que não previa a existência e nem a obrigatoriedade desta disciplina.

As atividades desenvolvidas pelos alunos foram orientadas e contextualizadas por meio de leituras e discussões de textos que também fundamentaram o desenho da disciplina, resultando na proposição dos eixos indicados.

1 Apesar de não havermos empreendido nenhuma avaliação rigorosa acerca das razõe pelas quais poucos alunos se matricularam na disciplina, temos algumas hipóteses formuladas. Acreditamos que um conjunto de fatores pode ter contribuído com esta situação: carga horária elevada de atividades obrigatórias a ser cumprida pelo alunos no semestre, pouca tradição da presença de disciplinas de ensino de geografia no currículo, professora responsável pela disciplina pouco conhecida dos alunos. 


\section{0 estudo de mapas e fotografias de livros didáticos que abordam o conceito de fronteira}

As atividades referentes a este eixo foram pensadas a partir da compreensão do currículo como representação. Como aponta Silva (2007), nossas formas de conhecer o mundo estão estritamente ligadas as nossas formas de representá-lo materialmente. Assim, todas as marcas visíveis e palpáveis dos modos como conhecemos o mundo na escola podem ser entendidas e estudadas considerando o conceito de representação.

Uma das questões implicadas no conceito de representação diz respeito à 'relação entre, de um lado, o 'real' e a 'realidade', e de outro, as formas pelas quais esse 'real' e essa 'realidade' se tornam presentes para nós - representados" (Silva, 2007, p.32). Segundo o autor, esta relação não é transparente nem especular, mas é sim construída socialmente e culturalmente, pois as representações são sempre fruto de um processo de produção que envolve tanto os mecanismos de funcionamento das linguagens, quanto as relações de poder circunscritas à sociedade.

Esta maneira de entender as formas pelas quais representamos e conhecemos o mundo na escola, mas também fora dela, tem efeito sobre nosso modo de pensar e agir no ensino de geografia. Silva (2007) diz que "o currículo, tal como a linguagem, não é um meio transparente, que se limita a servir de passagem para um 'real' que o conhecimento torna presente" (p.64). Desse modo, nem os livros didáticos de geografia e nem os mapas e fotografias que neles circulam podem ser tomados simplesmente como instrumentos ou recursos para a transmissão ou construção do conhecimento geográfico. Eles são em si formas de conhecimento cujos processos de produção e práticas de significação devem ser compreendidos e este foi o objetivo das atividades propostas no eixo.

A primeira atividade consistiu em levantar os mapas e fotografias que apareciam associados ao termo fronteira nas páginas de livros didáticos digitais de geografia. 0 formato digital foi escolhido em função dos mecanismos de busca que teríamos a disposição para identificar o material que queríamos coletar e, também, pela discussão que buscávamos promover em relação à textualidade e condições de produção dos livros didáticos na contemporaneidade.

Como argumenta Tonini (2011), o livro didático é a materialização de um currículo editado e, portanto, apresenta marcas atreladas à cultura escolar e à sociedade. Por conseguinte, ao analisarmos sua estrutura textual ao longo do tempo é possível notar mudanças de concepções de ensino-aprendizagem e de modos de comunicação. Acompanhando as transformações dos meios de comunicação e das tecnologias, os livros didáticos de geografia têm cada vez mais fragmentado os textos escritos e deslocado sua centralidade para as imagens, solicitando operações de aprendizagem mais complexas e formas de leitura menos sequenciais e lineares, como ocorre na interação com as mídias digitais no contexto da cultura atual.

Os livros didáticos selecionados para realizarmos esta atividade foram aqueles que possibilitavam o acesso livre na internet ${ }^{2}$. Desse modo, a pesquisa foi feita em três coleções diferentes ${ }^{3}$, destinadas ao Ensino Médio. Para realizar o levantamento dos mapas e fotografias que abordavam o conceito de fronteira, o seguinte procedimento foi realizado: a palavra fronteira foi digitada no sistema de busca de cada um dos livros que compunha as coleções, as páginas que apareciam como resultados da pesquisa eram salvas no computador e, então, os mapas e fotografias existentes nas páginas eram reproduzidos em um arquivo para posterior análise e discussão em sala de aula.

A análise dos mapas foi a segunda atividade proposta e, para tanto, levou em conta a temática das representações que apareciam associados ao conceito de fronteira nas páginas dos livros, bem como a métrica, a escala, a projeção e as variáveis visuais aplicadas. Tal análise foi embasada principalmente pela leitura e discussão de Fonseca e Oliva (2013), que problematiza o fundo do mapa contemporâneo e as relações da linguagem gráfica com a linguagem cartográfica.

A terceira atividade consistiu na análise das fotografias identificadas nos livros. Tal análise foi orientada, principalmente, pela leitura e discussão do texto de Hollman (2014). Buscando compreender os regimes visuais da questão ambiental nos livros didáticos de geografia da Argentina, a autora apresenta algumas estratégias metodológicas que possibilitam este trabalho. Dentre estas está a noção de montagem, que utilizamos na atividade para analisar os sentidos de fronteira que as coleções didáticas fazem circular pela linguagem fotográfica.

\section{A experimentação das linguagens fotográfica e cartográfica através de práticas que buscam alargar os sentidos de fronteira acentuados nos materiais didáticos}

Ao trabalhar as linguagens cartográfica e fotográfica em uma perspectiva mais cultural e discursiva, outro aspecto que buscamos explorar na disciplina foi a experiência de caminhos mais aptos a acolher a diferença e as múltiplas possibilidades de representação de mundo no ensino

\footnotetext{
2 O site www.abrileducacao.com.br/pnld2015/ disponibiliza algumas versões digitais de livros didáticos que participaram do Programa Nacional do Livro Didático, de 2015, promovido pelo Ministério da Educação. Os livros com os quais trabalhamos na disciplina foram encontrados neste portal.

3 As coleções consultadas foram: Fronteiras da Globalização (2013), Geografia Geral e do Brasil (2013) e, Geografia: O Mundo em Transição (2013).
} 
de geografia. Assim, tomando os mapas e as fotografias como formas de conhecimento em si e não somente como instrumentos didáticos, buscamos com elas construir outras fronteiras possíveis nas atividades propostas para este eixo.

Na discussão sobre o currículo como representação, Silva (2007) deixa claro que o "real" e a "realidade" que importam no conceito de representação não é aquela que lhe é anterior, mas aquela que a própria representação produz. Como diz o autor (2007), a representação "produz os objetos de que fala". Desse modo, pensar o uso das linguagens no ensino de geografia e na formação de professores não se trata somente de questionar as realidades que as linguagens produzem na geografia escolar, mas também de inventar maneiras de criar com elas outras realidades.

Para Oliveira Junior e Girardi (2011), ao assumirmos que as linguagens produzem o mundo, passamos a lidar com elas no ensino de geografia não somente "como elemento de um processo de comunicação, mas como fundamento de um processo de criação, de produção de pensamento sobre o espaço" (p.4). Com isso, os autores enfatizam que deixamos de focar apenas no conteúdo dos produtos das linguagens, isto é, o que elas representam ou deixam de representar para abordar sua própria natureza, ou seja, o modo como as linguagens operam, o que mobilizam. Nesta visão, todas as práticas que buscam efetivar nas diferentes linguagens a criação de novos sentidos e pensamentos sobre o espaço são entendidas como tendo em si mesmas uma dimensão pedagógica, "geradora de conhecimentos e saberes sobre o espaço geográfico", dizem eles (p.4).

A primeira atividade desenvolvida na disciplina com esta abordagem envolveu a linguagem cartográfica e a arte. Baseando-se no texto de Seemann (2012) sobre as estratégias para subverter a cartografia escolar, foi proposto que cada um dos alunos construísse um novo mapa a partir de uma das representações cartográficas encontradas nos livros didáticos consultados.

A segunda atividade proposta com o intuito de produzir novos sentidos para o conceito de fronteira se efetivou na linguagem fotográfica. Compreendendo a fotografia como um ato criativo conduzido pelo fotógrafo e não como um mero registro de natureza física, solicitamos que cada um dos alunos tirasse uma fotografia à luz da ideia de fronteira. Para cada uma das fotos elaboramos algumas questões e as trocamos entre os alunos. Cada aluno deveria, então, responder as questões relacionadas à fotografia criada por um dos seus colegas.

Esta parte da atividade buscou mostrar aos alunos que a criação de novos sentidos e pensamentos acerca do espaço com a fotografia não só pode ser efetivada no momento de produção das imagens, como também no momento de consumo das mesmas. Assim, procuramos indicar de que maneira podemos nos apropriar das fotos que já nos chegam prontas no mundo e na escola. Oliveira Junior e Soares (2013) nos ajudaram nesta tarefa ao apontarem, em seu texto, algumas possibilidades de fabulação com e através das fotografias.

Segundo esses autores, para retirar as fotografias do sentido fixo de documento do real, de modo a abri-las a outros significados, podemos: considerar o antes, durante e depois das imagens, deslocando as imagens para o cotidiano de nossas vidas; elaborar perguntas que indiquem múltiplas possibilidades de conversar com a linguagem fotográfica e o fotógrafo; inventar histórias para estas fotos, cercando-as da presença do fotógrafo e dos elementos da linguagem fotográfica (Oliveira Junior \& Soares, 2013). Foi o que buscamos realizar com as questões elaboradas para as fotos feitas pelos alunos.

\section{Fronteiras fixas: limites, divisões, problemas e conflitos}

\section{O estudo dos mapas dos livros didáticos}

Nos livros didáticos, como era de se esperar, a linguagem cartográfica aparece associada ao conceito de fronteira, principalmente, nos capítulos que abordam as temáticas: formação territorial e limites políticos de determinados países, migração e conflitos geopolíticos e territoriais. Quando se trata de território e Estado-Nação, a maior parte das representações cartográficas é em escala nacional (Alemanha, Brasil, China, Bolívia) e continental (Europa, América do Sul). No caso dos movimentos migratórios, as escalas utilizadas são mundial, nacional (Brasil) ou continental (Europa). Já para abordar a questão dos conflitos, os mapas apresentados nos livros contemplam uma variedade maior de escalas, indo do mundo a um regional intra-estadual (Reserva Raposa Serra do Sol). Mesmo assim, em nenhum destes temas, mapas em escalas locais que abrangem os limites de um município ou bairro, por exemplo, são empregados.

O termo fronteira é também bastante citado nos capítulos que abordam a regionalização (Brasil e mundo), e as temáticas físico-naturais e ambientais. Desse modo, encontramos mapas que nos remetem ao referido conceito ao representarem as regiões geoeconômicas do Brasil, a divisão do mundo em países desenvolvidos (norte) e subdesenvolvidos (sul), a divisão do mundo em civilizações (ocidental, latino-americana, Ortodoxa, árabe/mulçumana, africana, Budista e confuciana, xintoísta e hinduísta), as bacias hidrográficas e formas de relevo do Brasil, bem como as denominadas fronteiras agrícolas e energéticas do país.

Todos os mapas identificados utilizam a mesma métrica, isto é, o mesmo sistema de medidas para apreender e representar o espaço. Baseada na geometria euclidiana, este sistema concebe o espaço como um espaço de distâncias medidas em metros e, como coloca Fonseca e Oliva (2013), 
é a principal herança do fundo do mapa contemporâneo. Desta forma, todos os lugares representados nos mapas são contínuos e contíguos, ou seja, não apresentam lacunas nem rupturas.

Por falar em continuidade e contiguidade, a linha é o principal recurso gráfico implantado para representar as fronteiras de que falam os mapas que coletamos. Algumas vezes esta linha aparece tracejada, algumas vezes mais grossa, outras vezes mais fina e, em alguns momentos, também na forma de seta. Outro recurso utilizado para representar as fronteiras nos mapas é o elemento zonal, por meio do qual é possível diferenciar áreas e regiões.

No que se refere às projeções utilizadas, foi possível perceber certa variedade de projeções aplicadas nos mapas em pequena escala. No quadro abaixo podemos observar alguns mapas mundiais com projeções diferentes encontradas nos livros.

\section{O estudo das fotografias dos livros didáticos}

Para Hollman (2014), a montagem pode servir para desmontar os regimes visuais que ajudam a conformar nossos modos de olhar para o mundo. Em seu trabalho, ela utiliza esta estratégia para identificar a persistência e sistematização de discursos acerca do ambiental nos livros didáticos de geografia da Argentina. Na experiência de formação de professores que narramos aqui, utilizamos a montagem para dar a ver os regimes visuais do conceito de fronteira presentes nos livros didáticos que investigamos, tomando como base as fotografias que neles circulam. Assim, cada aluno ${ }^{4}$ que cursou a disciplina deveria montar uma série de imagens com o conjunto das fotos coletadas, buscando responder: o que a série nos autoriza ou desautoriza a olhar?

Uma das séries elaboradas é apresentada abaixo sob o título "A fronteira como conflito".

Marina 5 , a aluna autora da montagem, diz em seu trabalho que "a fronteira como conflito é significada a partir de elementos centrais que se repetem em todas as situações: forte policiamento ou militarismo, armas e um forte esquema de segurança nas fronteiras". Portanto, para ela, a série nos autoriza a olhar as fronteiras com "temor e tensão", aceitando "que o exercício do poder é necessário para conter os interesses daquele território perante as externalidades que contrapõem as necessidades e visões defendidas", completa a aluna.

A série apresentada a seguir foi denominada por seu autor de "Fronteirasproblema”.

Além do título desta montagem nos remeter a ideia da montagem anterior, algumas fotografias são comuns às duas. No entanto, Bruno, o aluno que realizou esta segunda série, diz que "Fronteiras-problema" significa "limites rígidos os quais não se deveria passar, e que só são atravessados em casos de grandes problemas ou necessidades extremas". Com isso, para ele, as imagens "autorizam uma noção normativa de fronteira, na qual a fronteira aparece como algo, um limite que deve ser respeitado, a não ser em casos de vida ou morte".
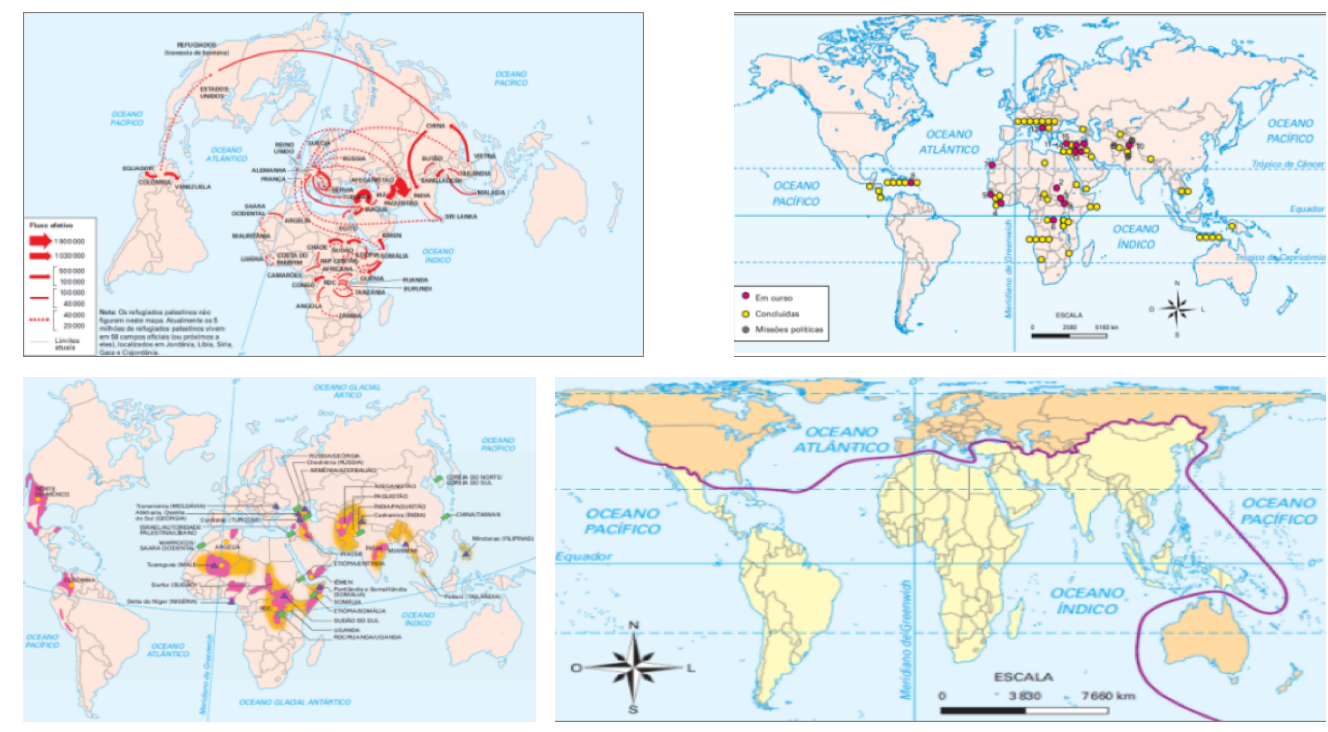

Figura 1. Projeções encontradas em alguns mapas mundiais das coleções didáticas

\footnotetext{
4 Apesar as atividades terem sido propostas para todos os alunos(as) que cursavam a disciplina, nem todos(as) fizeram ou entregaram os trabalhos.

5 Todos os nomes de alunos(as) citados no texto são fictícios.
} 

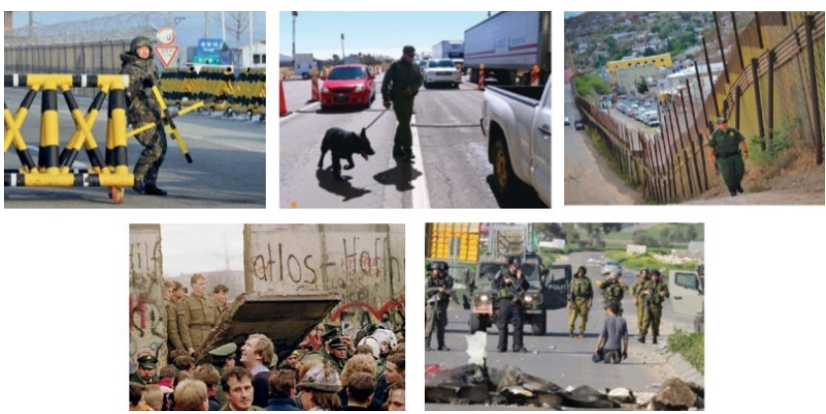

Figura 2. Série fotográfica "A fronteira como conflito", composta por imagens das coleções didáticas.
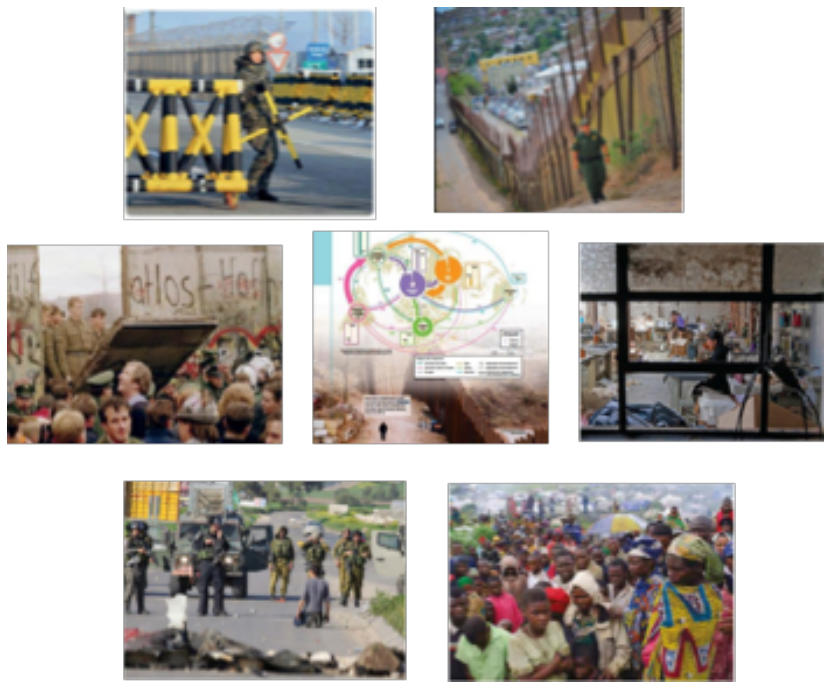

Figura 3. Série fotográfica "Fronteiras-problema", composta por imagens das coleções didáticas

Interessante também é aquilo que, para Bruno, estas fotografias nos desautorizam a olhar, isto é, os sentidos de fronteira que elas acabam silenciando em função da persistência do referido discurso. Assim, em suas palavras:

As imagens selecionadas desautorizam o discurso de fronteiras enquanto encontro, possibilidades, potencialidades oriundas do encontro de campos diversos, mas nem por isso opostos. Desautoriza também o discurso de fronteiras como linhas fluidas, que nem sempre representam grandes descontinuidades.

\section{Fronteiras móveis: desejos, memórias, possibilidades e escolhas}

\section{O mapa-arte}

Os mapas abaixo participaram do processo de criação de Marina nesta atividade. A partir de seu trabalho, a representação da figura 4 se transformou na representação da

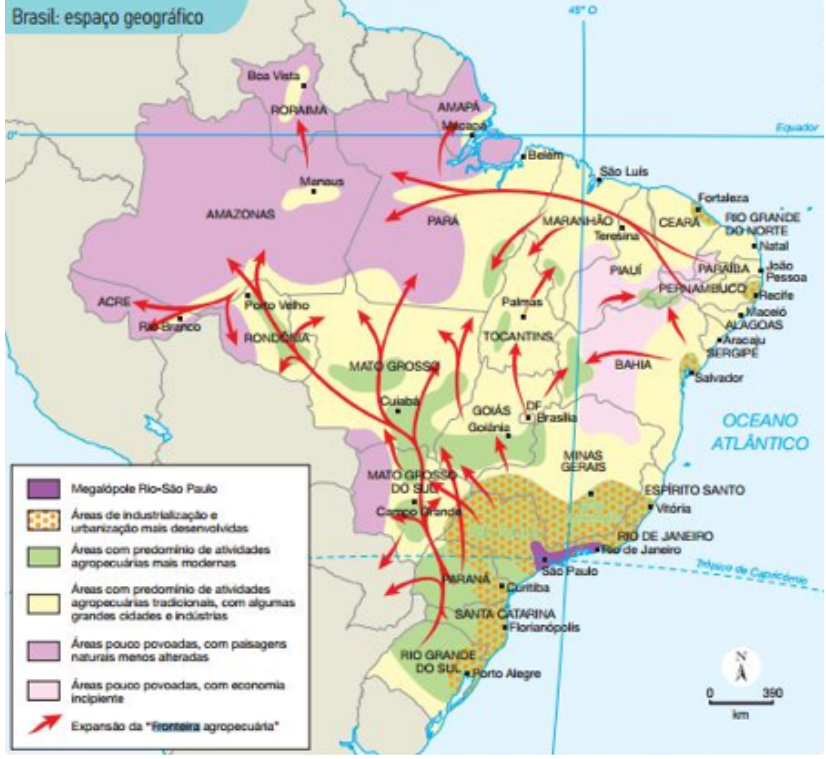

Figura 4: mapa da coleção didática Geografia Geral e do Brasil, vol. 3, 2013.

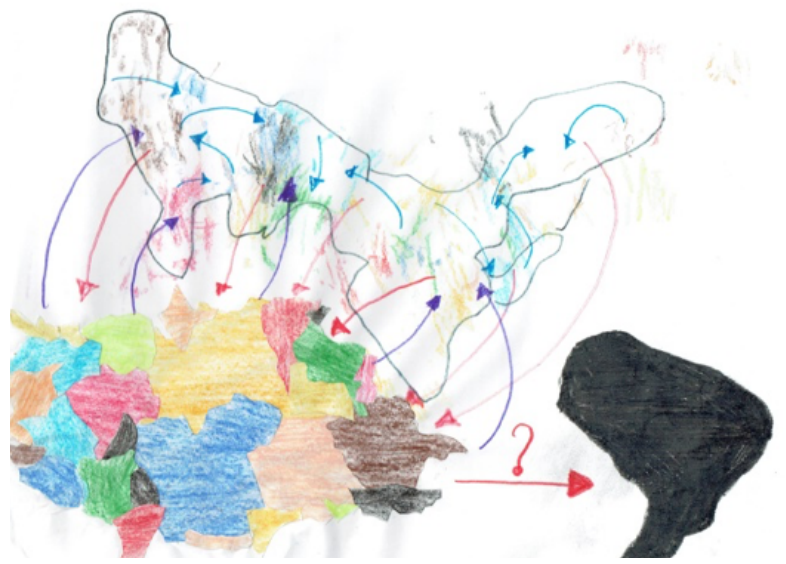

Figura 5: mapa-arte criado por Marina.

No texto que escreveu sobre a composição de seu novo mapa, a aluna nos conta que a ideia inicial era "recortar os territórios políticos dos estados do país, como forma de 'montar um novo quebra cabeças', já que não concordava com a maioria das divisões propostas no mapa original. Para tanto, ela recortou os estados brasileiros do mapa e os virou do avesso para pintá-los e depois arranjá-los de uma nova maneira no papel.

Para colorir o verso dos recortes, Marina utilizou uma folha em branco como forma de apoio para quando o traço saísse dos limites do recorte. Ao terminar esta tarefa, ela diz que identificou, nesta folha, um padrão que lhe fazia lembrar um mapa mundie, por isso, imprimiu um contorno mais forte ao padrão. Posteriormente, os "pedaços do Brasil", como diz a aluna, foram colados de forma aleatória sobre a folha e, então, correlacionados com um desenho do que seria "a representação 'correta' do Brasil" menciona. 
Marina coloca que não estava preocupada com o resultado de seu processo de criação, pois seu objetivo desde o inicio era desconstruir. "O importante era o motivo que me fez agir daquela forma, e não o processo em si ou a conclusão dele. Pensei em como as relações são fragmentadas e dinâmicas e em como uma representação tão fechada não a reflete".

Bruno escolheu o mapa da figura 6 para construir seu mapa-arte (figura 7).

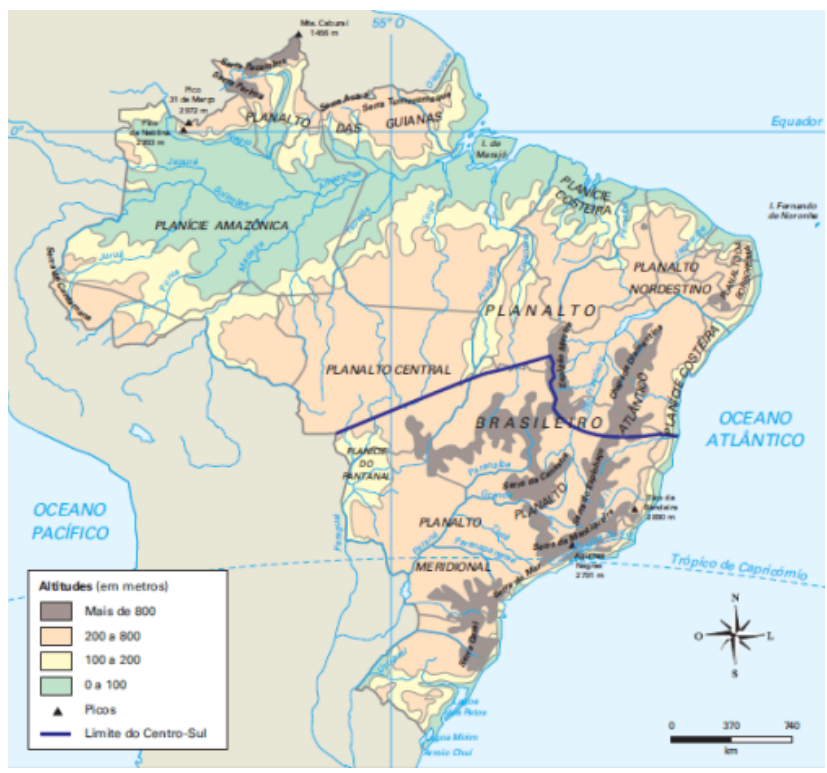

Figura 6: mapa da coleção didática Geografia: O Mundo em Transição, vol. 3, 2013.

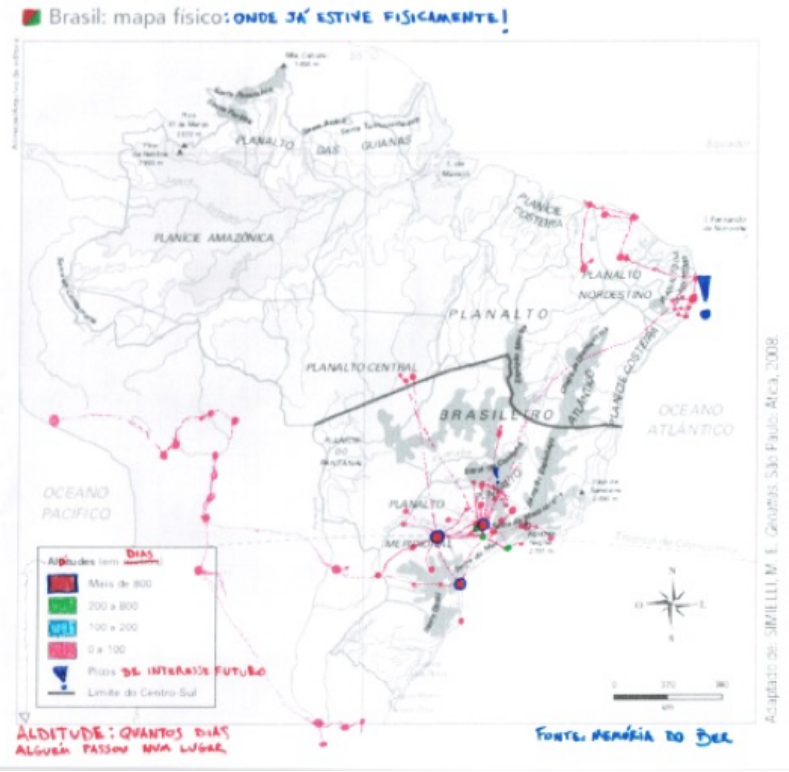

Figura 7: mapa-arte criado por Bruno.
Ele conta que no momento em que se deparou com a tarefa de "escoIher qualquer mapa e fazer qualquer coisa com ele", ele parou para se perguntar:

O que eu QUERO fazer agora? Quais são os meus interesses mais vivos agora? O que eu posso fazer, a partir de um mapa, que me dê PRAZER? O que eu posso CRIAR agora, partindo desse mapa do "Brasil físico", pra chegar a algo que faça sentido pra mim agora?

Sua resposta foi: "Quero pensar nos locais pra onde quero ir!". Para isso, decidiu começar pelos lugares onde já esteve e o resultado está logo abaixo.

Como é possível identificar no mapa-arte, Bruno substituiu o sistema de medidas em metro da legenda do mapa original por um sistema de medidas em dia, o qual chamou de "alditude", em uma brincadeira com a palavra "altitude". 0 aluno relata que o grande desafio do mapeamento foi "marcar, em um mapa mais geológico do Brasil, no qual não existem as delimitações políticas dos estados, quais os lugares onde já morei ou passei".

Interessante notar os pensamentos de Bruno acerca da sua relação com o espaço a partir do mapa que criou. Ele diz:

o eixo da minha existência até hoje esteve absolutamente concentrado na metade sul do Brasil! E em especial, nos estados de PR e SP. Isso contrasta muito com meus desejos futuros de lugares para os quais penso em me mudar, que estão predominantemente em um espaço que eu conheço pouco e no qual tive pouca vivência: Pernambuco. Se eu realmente for morar lá, será quase uma "revolução geográfica" na história recente da minha família! Há 60 anos que todos os meus ancestrais diretos vivem no estado de SP, ou no Paraná nos últimos 28 anos, para onde meus pais foram em 1988, onde nasci. Mas e antes disso?

\section{Perguntas sobre/para uma fotografia}

As fotografias abaixo foram feitas por Marina e Daniel.

Para cada foto, elaboramos questões que pediam aos alunos para: a) descrever o que viam; b) elaborar perguntas a pessoa que tirou a foto e; c) escrever uma história para a imagem. Para a foto da figura 8, esta história deveria levar em conta o que a pessoa que tirou a foto fazia naquele lugar e horário. Já para a imagem da figura 9 , o aluno deveria se colocar no ponto de vista do autor da foto e contar, por meio de uma carta, o que mais poderia sentir e perceber através daquela janela.

O que você acha desta grade e deste muro? Se você pudesse mudar algo desta paisagem, você derrubaria algum deles? Ou mudaria algo neles? 
Como você se sente ao passar entre o muro e a grade? Que comportamentos e sentimentos eles parecem estimular em você? Qual a importância deste prédio, na sua opinião?

Já Daniel elaborou as seguintes perguntas para o autor da segunda foto acima: "Qual a hora da foto? O que você levou em consideração para escoIher esse lado e não o outro? Por que de dia? Por que na sua própria casa?"

\section{Considerações para o futuro}

De que maneira a disciplina e as atividades propostas contribuíram com a formação dos futuros professores de geografia? Parece-me que

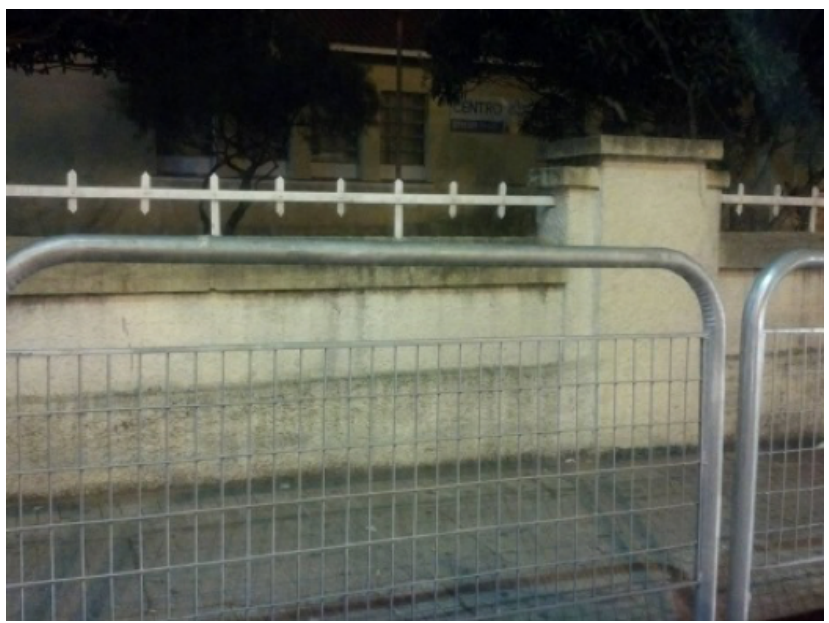

Figura 8: fotografia criada por Marina de diversas formas se considerarmos os pensamentos e conhecimentos que os estudantes mobilizaram nas práticas de linguagem realizadas. Com os mapas, identificaram que as fronteiras podem criar limites e divisões, mas também despertar desejos e memórias, dependendo de quão aberta estão ao imprevisto e as nossas imaginações. Com as fotografias, entenderam que não só problemas e conflitos fazem parte das fronteiras, como também possibilidades e escolhas, se mudarmos o nosso ponto de vista e modo como olhamos ou perguntamos. As fronteiras, então, podem ser fixas e móveis, dentro e fora da escola, no momento em que compreendemos que as linguagens produzem o mundo e com elas decidimos transformá-lo no ensino de geografia.

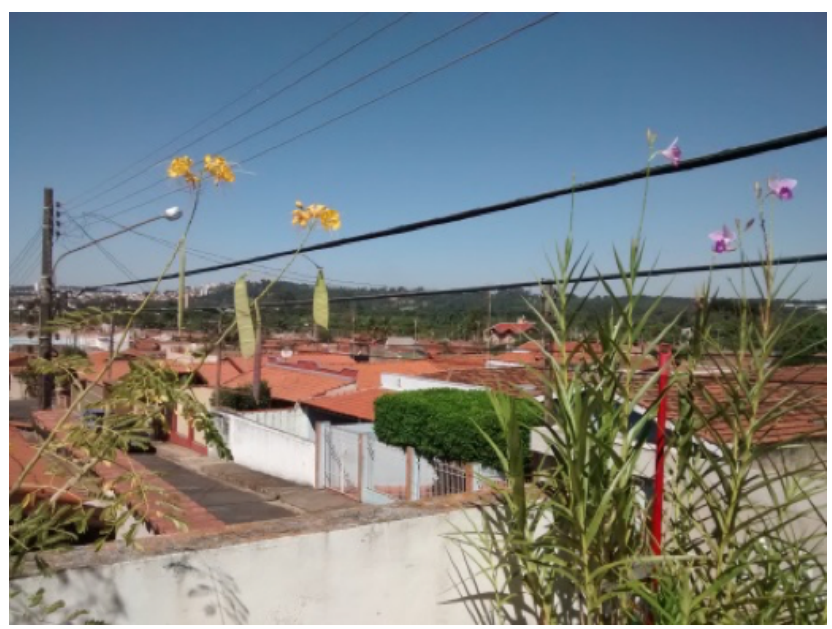

Figura 9: fotografia criada por Daniel

\section{Referências}

Fonseca, F. e Oliva, J. (2013). Cartografia. São Paulo: Melhoramentos.

Hollman, V. (2014). Regimes visuais da questão ambiental nos livros didáticos de geografia na Argentina. Revista Brasileira de Educação em Geografia, 4(8), 221-240.

Oliveira Junior, W., e Girardi, G. (2011). Diferentes linguagens no ensino de geografia. Anais do XI ENPEG, 1 p. 1-9.see

Oliveira Junior, W., e Soares, E. (2013). Fotografias didáticas e geografia escolar entre evidências e fabulações. Percursos, 13(2), 114-133.

Seemann, J. (2012). Subvertendo da cartografia escolar no Brasil. Revista Geografares, 12, 138-174.

Silva, T. (2007). O currículo como fetiche: a poética e a política do texto curricular. Belo Horizonte: Autêntica.

Tonini, I. (2011). Livro didático: textualidades em rede? Em I. Tonini, L. Goulart, R. Martins, et al. (Orgs). O ensino da geografia e suas composições curriculares. (pp.145-154). Porto Alegre: UFRGS. 